\title{
Two-Dimensional COF-Three-Dimensional MOF Dual-Layer Membranes with Unprecedentedly High H2/CO2 Selectivity and Ultrahigh Gas Permeabilities
}

\author{
Saikat Das, ${ }^{\dagger}$ Teng Ben, ${ }^{*}{ }^{\dagger}$ Shilun Qiu ${ }^{\dagger}$ and Valentin Valtchev $\dagger$, " \\ ${ }^{\dagger}$ Department of Chemistry, Jilin University, Changchun 130012, P. R. China \\ "Normandie University, ENSICAEN, UNICAEN, CNRS, Laboratoire Catalyse et Spectrochimie, 6 Marechal Juin, \\ 14050 Caen, France
}

Supporting Information Placeholder

\begin{abstract}
Covalent organic framework (COF) membranes have emerged as state-of-the-art membranes with exceptional gas separation performances. However, the COF membranes are restricted to three-dimensional (3D) COFs, while the two-dimensional (2D) COF membrane remains a relatively uncharted territory. In addition, the major part of the scientific fraternity working in this field shares the dream to prepare $2 \mathrm{D}$ COF membranes with crystallographic preferential orientation. Here, we present a general strategy for the fabrication of oriented $2 \mathrm{D}$ COF membranes which is based on the incorporation of an intermediate metal-organic framework (MOF) layer. The $2 \mathrm{D}$ COF membrane is endowed with real ordered one-dimensional $(\mathrm{iD})$ channels. This specially designed membrane that comprises two judiciously selected porous frameworks shows ultrahigh gas permeability and selectivity far surpassing the present Robeson upper bound. This contribution paves a new avenue to explore oriented 2D COF membranes as prospective high-performing membranes rendering a sustainable route for $\mathrm{H}_{2} / \mathrm{CO}_{2}$ separation.
\end{abstract}

Porous organic framework membranes ${ }^{1-7}$ with a preferred orientation are one of the most coveted membrane architectures in gas separation owing to highly efficient intracrystalline gas diffusion and reduced non-selective intercrystalline gas diffusion. 2D inorganic porous material such as zeolite, ${ }^{8-}$ ${ }^{10} \mathrm{MOF}^{11-16}$ etc. oriented membranes with high selectivity are routinely fabricated by secondary growth method using substrates with oriented seed layers. ${ }^{17,18}$ Importantly, the performance of a gas separation membrane ${ }^{19,20}$ depends not only on high selectivity but also on high permeability. $2 \mathrm{D} \mathrm{COFs}{ }^{21-}$ ${ }^{26}$ have relatively large pore sizes compared to the sizes of the permeating gas molecules which contribute to high permeability. On the other hand, a membrane with preferential orientation presents high selectivity. Scientists always strive for membranes that outperform the Robeson upper bound ${ }^{27}$ which represents the permeability-selectivity trade-off in the field of gas separation membranes.

The $\pi$-stacked columns of $2 \mathrm{D}$ COFs that can contribute to direct pathways for gas transport render $2 \mathrm{D}$ COFs as highly promising materials for gas separation membranes. However, it remains a formidable challenge from fabrication perspective to attain an oriented $2 \mathrm{D}$ COF membrane considering that the $2 \mathrm{D} \mathrm{COF}$ layers tend to be randomly aligned to each other. A few examples of the preparation of $2 \mathrm{D}$ COF membranes $^{1,3,4}$ did not report preferentially oriented COF layer.

To tackle this issue, we herein adopted a specially designed MOF membrane that provides the binding sites along the vertical direction to anchor the $2 \mathrm{D}$ COF structural building units. Besides, the covalent bond formation between the $2 \mathrm{D}$ COF building units parallel to the MOF membrane surface enables the COF crystals to grow along the MOF membrane surface thereby favoring the growth of a continuous $2 \mathrm{D} \mathrm{COF}$ layer. The interlayer interactions guide the development of the stacking structure thereby enabling the formation of ordered $1 \mathrm{D}$ channels oriented perpendicular to the MOF membrane surface. Hence the present fabrication approach allows us to effectively attain the $2 \mathrm{D}$ COF crystals growing along the MOF membrane surface as well as realize the COF channels oriented perpendicular to the entire membrane surface (Figure 1).

A porous silica disk employed as substrate was coated with a polyaniline emeraldine base layer which provides amine groups functionalized surface. Thereafter the polyaniline base-functionalized $\mathrm{SiO}_{2}$ disk (Figure $\mathrm{S} 1 \mathrm{a}$ ) was used for the fabrication of UiO- $66^{28}$ membrane (Figure $\mathrm{S} 1 \mathrm{~b}$ ). On the surface of the UiO-66 membrane, there are many unsaturated metal sites. These unsaturated metal sites played a vital role in the growth of the ${ }_{2} \mathrm{D} \mathrm{H}_{2} \mathrm{P}-\mathrm{DHPh} \mathrm{COF}^{22 \mathrm{c}}$ film atop the UiO-66 layer. More precisely, the coordinatively unsaturated zirconium cations of $\mathrm{UiO}-66$ interact with the amine groups of porphyrin as evident from the $\mathrm{Zr}-\mathrm{N}$ coordinate bond at 
$424 \mathrm{~cm}^{-1}$ of the Fourier Transformed Infrared (FTIR) spectrum

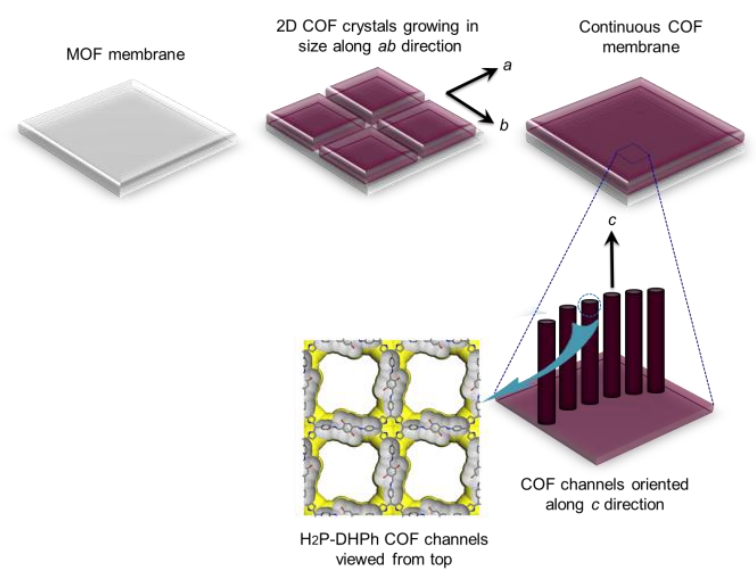

Figure 1. Schematic representation of how to control the growth of a continuous 2D COF membrane along $a b$ (lateral) direction as well as maintain the orientation of the COF channels along $c$ (vertical) direction.

(Figure $\mathrm{S}_{3}$ ). Strong chemical bonding between $\mathrm{Zr}$ and $\mathrm{N}$ seals the COF and MOF layers via a thin interlayer of interpenetrating crystals. The fabrication process of $\left[\mathrm{H}_{2} \mathrm{P}-\mathrm{DHPh} \mathrm{COF}\right]-$ [UiO-66] composite membrane is outlined in Figure 2 and the details are provided in the SI.

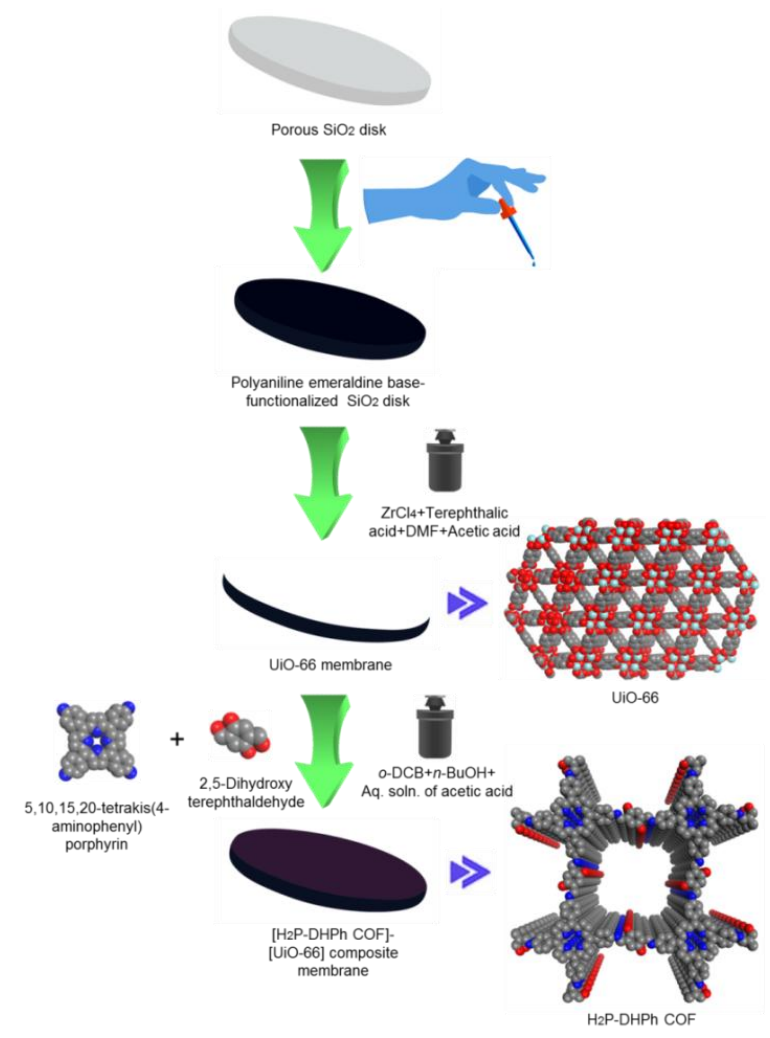

Figure 2. Process flowchart illustrating the fabrication of [ $\left.\mathrm{H}_{2} \mathrm{P}-\mathrm{DHPh} \mathrm{COF}\right]-[\mathrm{UiO}-66]$ composite membrane ( $\mathrm{Zr}$ : cyan, $\mathrm{O}$ : red, $\mathrm{N}$ : blue, C: gray. $\mathrm{H}$ atoms are excluded for clarity).
Optical photographs presented in Figure Sia,b reveal that the surface of silica disc is uniformly covered with polyaniline and UiO-66 layers. X-ray diffraction analysis of the UiO-66 membrane revealed the formation of pure highly crystalline UiO-66 material (Figure S2). Scanning electron microscopy (SEM) study showed the formation of continuous and uniform layer of UiO-66 containing closely-packed 1-2 $\mu \mathrm{m}$ octahedral crystals (Figure $\mathrm{S} 1 \mathrm{~b}$ ). As can be seen in Figures $\mathrm{S} 1 \mathrm{~b}$ and $3 \mathrm{a}$, the white surface of the UiO-66 membrane was regularly covered with a dark purple layer of $\mathrm{H}_{2} \mathrm{P}-\mathrm{DHPh}$ COF. Cross-sectional SEM images and the corresponding elemental mapping (Figure $3 \mathrm{c}$-e) of the composite membrane clearly distinguish the COF and MOF layers, each of them with thickness of ca. $60 \mu \mathrm{m}$. Figure $3 \mathrm{~b}$ presents the XRD patterns of $\mathrm{H}_{2} \mathrm{P}-\mathrm{DHPh} \mathrm{COF}$ powder and [ $\mathrm{H}_{2} \mathrm{P}-\mathrm{DHPh} \mathrm{COF}$ [UiO-66] composite membrane. The XRD pattern of composite membrane contains solely the Bragg peaks of COF material thereby implying that the top layer is composed of pure $\mathrm{H}_{2} \mathrm{P}-\mathrm{DHPh} \mathrm{COF}$. In addition to 100 and 200 characteristic diffraction peaks of $\mathrm{H}_{2} \mathrm{P}-\mathrm{DHPh} \mathrm{COF}$ at $3.44^{\circ}(2 \theta)$ and $6.90^{\circ}$ $(2 \theta)$ respectively, a strong peak at $21.34^{\circ}(2 \theta)$ is observed. The latter peak is attributed to oo1 Bragg reflection, which is relatively weak in the powder XRD pattern. The crystallographic preferred orientation $(\mathrm{CPO})^{29,30}$ of $\left[\mathrm{H}_{2} \mathrm{P}-\mathrm{DHPh} \mathrm{COF}\right]-[\mathrm{UiO}-$ 66] composite membrane and $\mathrm{H}_{2} \mathrm{P}-\mathrm{DHPh} \mathrm{COF}$ powder (synthesized in pyrex tube) in Figure $3 \mathrm{~b}$ is evaluated using ${ }^{29,30}$ :

$$
\mathrm{CPO}_{\mathrm{oo1} / \mathrm{100}}=\frac{\left[\left(\frac{I_{001}}{I_{100}}\right)_{\text {mem }}-\left(\frac{I_{001}}{I_{100}}\right)_{\text {pow }}\right]}{\left(\frac{I_{001}}{I_{100}}\right)_{\text {pow }}}
$$

where $I$ denotes the integrated intensity of the corresponding reflection at the specified peak, mem denotes the $\left[\mathrm{H}_{2} \mathrm{P}-\right.$ DHPh COF]-[UiO-66] composite membrane and pow the $\mathrm{H}_{2} \mathrm{P}-\mathrm{DHPh} \mathrm{COF}$ powder.

A membrane shows orientation when the CPO values $\geq 1$. $^{31}$ The CPO for the (ool) and (100) reflections is about 49. The intense oo1 peak in the XRD pattern of composite membrane reveals that the COF layer is oriented along this plane. The preferential orientation of the $2 \mathrm{D}$ COF film along the oor face can be explained with the plate-like crystals morphology. Consequently, the channel system runs along the normal of membrane surface. $2 \mathrm{D}$ COF crystals following faster growth along out-of-plane direction grow fast and overpower the slower crystals with in-plane orientations. As a result the COF crystals accompanying fastest growth along the direction perpendicular to the membrane plane dictate the preferential orientation of the $2 \mathrm{D}$ COF layer. To monitor the integrity of the $2 \mathrm{D}$ COF film in the course of its growth, we performed the XRD analyses on the COF film after 1 day, 2 days and 2.5 days of solvothermal growth. The $\mathrm{H}_{2} \mathrm{P}-\mathrm{DHPh}$ COF crystals cover the UiO-66 intermediate layer with uniform and intimately intergrown $60 \mu \mathrm{m}$ thick film.

In the present work we show that a highly oriented $2 \mathrm{D}$ COF layer can be synthesized. The generation of the COF layer is promoted by the chemical interaction with modified and thus highly reactive intermediate MOF layer of the composite membrane. Consequently, the interpenetration of the COF and MOF crystals leads to a thin interlayer with intimately intergrown MOF and COF crystals. Further, the 

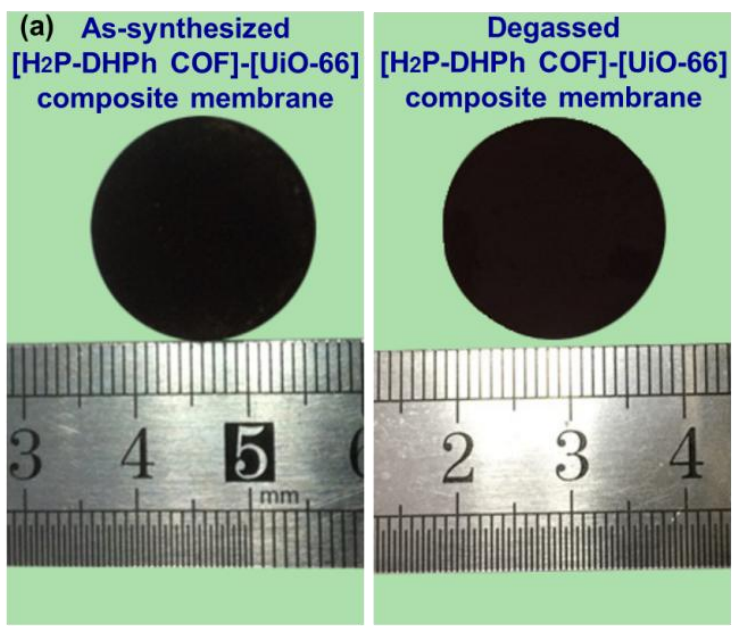

(b)

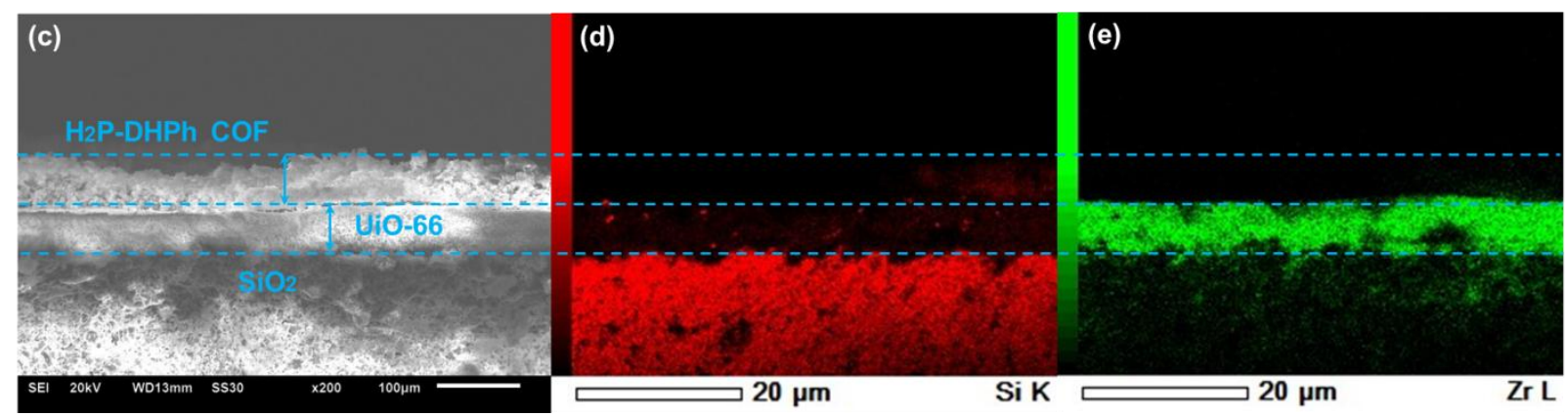

Figure 3. (a) Optical photographs of $\left[\mathrm{H}_{2} \mathrm{P}-\mathrm{DHPh} \mathrm{COF}\right]-[\mathrm{UiO}-66]$ composite membrane. (b) XRD patterns of $\mathrm{H}_{2} \mathrm{P}-\mathrm{DHPh} \mathrm{COF}$

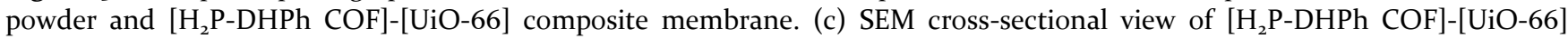
composite membrane. (d) Energy-dispersive X-ray spectroscopy (EDS) elemental mapping of silicon. (e) EDS elemental mapping of zirconium.

growth of COF layer is controlled by the morphological feature (plate-like morphology) of $\mathrm{H}_{2} \mathrm{P}-\mathrm{DHPh} \mathrm{COF}$. The porosity of $\mathrm{H}_{2} \mathrm{P}-\mathrm{DHPh} \mathrm{COF}$ and UiO-66 was examined from the $\mathrm{N}_{2}$ gas sorption analysis (Figure S6). We also carried out the stability tests of $\mathrm{H}_{2} \mathrm{P}-\mathrm{DHPh} \mathrm{COF}$ and $\mathrm{UiO}-66$ (Figures $\mathrm{S}_{4}, \mathrm{~S}_{5}$ ).

Gas permeation through the $\left[\mathrm{H}_{2} \mathrm{P}-\mathrm{DHPh} \mathrm{COF}\right]-[\mathrm{UiO}-66]$ composite membrane was studied using a gas chromatograph. As can be seen in Figure $4 \mathrm{~b}, \mathrm{H}_{2}$ gas with a kinetic diameter of $0.289 \mathrm{~nm}$ permeates considerably faster than $\mathrm{CO}_{2}$ (kinetic diameter $0.33 \mathrm{~nm}$ ) through the composite membrane. In membrane-based gas separation, the membrane layer that is at the helm of permeability and selectivity is called selective layer. Hence the selective layer of the composite membrane in this study encompasses the constituent COF and MOF layers as well as the interlayer between them. The thickness of the selective layer in the [ $\left.\mathrm{H}_{2} \mathrm{P}-\mathrm{DHPh} \mathrm{COF}\right]-$ [UiO-66] composite membrane is ca. $120 \mu \mathrm{m}$. The gas separation capability of the $\left[\mathrm{H}_{2} \mathrm{P}-\mathrm{DHPh} \mathrm{COF}\right]-[\mathrm{UiO}-66]$ composite membrane was evaluated by the separation of $1: 1$ binary gas mixture of $\mathrm{H}_{2} / \mathrm{CO}_{2}$ at room temperature and 1 bar pressure. The UiO-66 membrane gives commendable performance in terms of $\mathrm{H}_{2}$ permeability and $\mathrm{H}_{2} / \mathrm{CO}_{2}$ single and mixture separation selectivity. ${ }^{32}$ Notwithstanding the satisfactory performance of UiO-66 membrane, the phenomenal enhancement in gas separation selectivity was achieved after the crystallization of $2 \mathrm{D} \mathrm{H}_{2} \mathrm{P}-\mathrm{DHPh} \mathrm{COF}$ layer. The $\left[\mathrm{H}_{2} \mathrm{P}-\mathrm{DHPh}\right.$ COF]-[UiO-66] composite membrane features an ideal $\mathrm{H}_{2} / \mathrm{CO}_{2}$ selectivity of 49.1, whilst maintaining comparable $\mathrm{H}_{2}$ permeability (253188.7 Barrer) with UiO-66 membrane. The composite membrane exhibits a $\mathrm{H}_{2} / \mathrm{CO}_{2}$ mixture selectivity of 32.9, which is around four-fold enhancement in respect to the UiO-66 membrane in addition to increasing the $\mathrm{H}_{2}$ permeability to 10834 Barrer. Importantly, the $\left[\mathrm{H}_{2} \mathrm{P}-\mathrm{DHPh}\right.$ COF]-[UiO-66] composite membrane outdoes the Robeson upper bound for $\mathrm{H}_{2} / \mathrm{CO}_{2}$ separation. A comparative $\mathrm{H}_{2} / \mathrm{CO}_{2}$ separation performance analysis of polymer membranes is presented in the Robeson upper bound plot (Figure 4a).
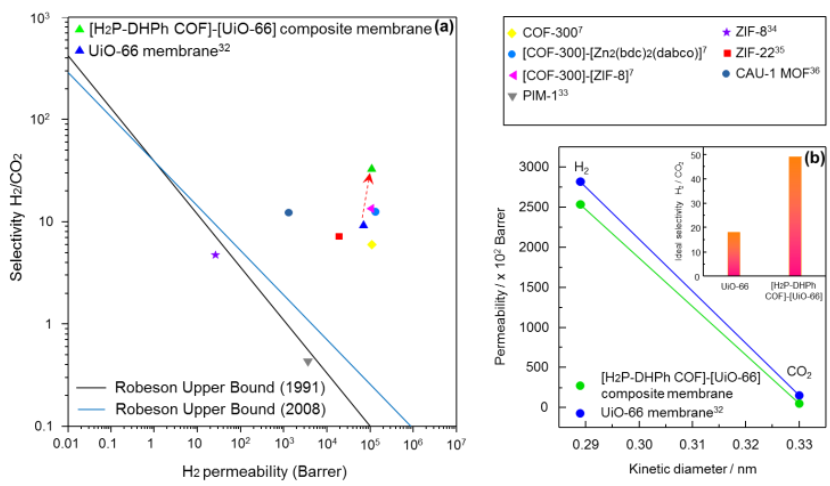

Figure 4. (a) Robeson upper bound plot of $\mathrm{H}_{2} / \mathrm{CO}_{2}$ selectivity versus $\mathrm{H}_{2}$ permeability for $\left[\mathrm{H}_{2} \mathrm{P}-\mathrm{DHPh} \mathrm{COF}\right]-[\mathrm{UiO}-66]$ composite membrane compared with state-of-the-art membranes $^{7,33^{-36}}$. The enhancement in separation selectivity of the composite membrane compared to the UiO-66 membrane ${ }^{32}$ 
is indicated by a red dashed line with an arrowhead. (b) Single gas $\left(\mathrm{H}_{2}\right.$ and $\left.\mathrm{CO}_{2}\right)$ permeability through the UiO-66 membrane and [ $\left.\mathrm{H}_{2} \mathrm{P}-\mathrm{DHPh} \mathrm{COF}\right]-[\mathrm{UiO}-66]$ composite membrane as a function of kinetic diameter of the gas molecules at room temperature and 1 bar. Inset: Ideal $\mathrm{H}_{2} / \mathrm{CO}_{2}$ selectivity of the UiO-66 membrane and $\left[\mathrm{H}_{2} \mathrm{P}-\mathrm{DHPh} \mathrm{COF}\right]-[\mathrm{UiO}-66]$ composite membrane.

\section{"Ideal separation factor.}

Table 1. $\mathrm{H}_{2} / \mathrm{CO}_{2}$ single and binary mixture (1:1) gas separation performance of $\left[\mathrm{H}_{2} \mathrm{P}-\mathrm{DHPh} \mathrm{COF}\right]-[\mathrm{UiO}-66]$ composite membrane at room temperature and 1 bar.

\begin{tabular}{|c|c|c|c|c|c|}
\hline \multirow{2}{*}{ Membranes } & \multirow{2}{*}{$\begin{array}{c}\text { Knudsen } \\
\text { selectivity }\end{array}$} & \multicolumn{2}{|c|}{ Single gas } & \multicolumn{2}{|c|}{ Mixture gas } \\
\cline { 3 - 6 } & & $\begin{array}{c}\mathrm{P}\left(\mathrm{H}_{2}\right)^{\top} \\
(\mathrm{Barrer})\end{array}$ & $\begin{array}{c}\mathrm{ISF} \\
\left(\mathrm{H}_{2} / \mathrm{CO}_{2}\right)^{\top}\end{array}$ & $\begin{array}{c}\mathrm{P}\left(\mathrm{H}_{2}\right)^{\top} \\
(\mathrm{Barrer})\end{array}$ & $\begin{array}{c}\mathrm{SF} \\
\left(\mathrm{H}_{2} / \mathrm{CO}_{2}\right)^{\prime}\end{array}$ \\
\hline $\begin{array}{c}{\left[\mathrm{H}_{2} \mathrm{P}-\mathrm{DHPh}\right.} \\
\mathrm{COF}]-[\mathrm{UiO}- \\
66] \text { composite } \\
\text { membrane }\end{array}$ & 4.7 & 253188.7 & 49.1 & 108341.3 & 32.9 \\
\hline
\end{tabular}

${ }^{\top} \mathrm{P}$ denotes permeability in Barrer $\left(1\right.$ Barrer $=3.347 \times 10^{-16}$ $\left.\mathrm{mol} \cdot \mathrm{m}^{-1} \cdot \mathrm{s}^{-1} \cdot \mathrm{Pa}^{-1}\right)$.

'ISF and SF denote ideal separation factor and separation factor, respectively.

High-resolution transmission electron microscopy (HRTEM) was employed to study the spatial organization of the composite membrane (Figure $5 \mathrm{~b}$ ). The membrane comprises two parts, the layered $\mathrm{H}_{2} \mathrm{P}$-DHPh COF sheets and the MOF (as evident in the bottom of the TEM image) characterized with sharp octahedral morphology (Figure $5 \mathrm{~b}$ ). The inset of Figure $5 \mathrm{~b}$ shows the selected area electron diffraction (SAED) pattern of the MOF part of the composite membrane. The energy-dispersive X-ray spectroscopy (EDS) spectrum presented in Figure $5 \mathrm{~d}$ shows zirconium, thereby indicating that the crystal with octahedral features at the bottom of the TEM image is indeed UiO-66. Crystalline COF domains can be recognized by the straight porous channels with interlayer spacing of $2.0 \pm 0.1 \mathrm{~nm}$ (Figure 5c). The intimate interaction between MOF and COF parts of the membrane can be seen from the interlayer image of the composite membrane.

The composite membrane comprises materials with pores substantially larger than the kinetic diameters of the permeating gas molecules. Thus the flux of the permeating gas is very high. In order to reach high selectivity we judiciously selected two porous frameworks so as to exhibit lower isosteric enthalpies of adsorption to $\mathrm{H}_{2}$ than to $\mathrm{CO}_{2}$. The isosteric enthalpies of adsorption of $\mathrm{H}_{2}$ for $\mathrm{H}_{2} \mathrm{P}-\mathrm{DHPh} \mathrm{COF}$ (Figure S8b) and UiO-66 (Figure $\mathrm{S} 7 \mathrm{~b}$ ) are lower than those of $\mathrm{CO}_{2}$ for $\mathrm{H}_{2} \mathrm{P}-\mathrm{DHPh} \mathrm{COF}$ (Figure S8d) and UiO-66 (Figure $\mathrm{S} 7 \mathrm{~d}$ ). Consequently, high selectivity to $\mathrm{H}_{2}$ was achieved. Besides the above factors, we ascribe the exceptional $\mathrm{H}_{2} / \mathrm{CO}_{2}$ mixture gas separation performance of the $\left[\mathrm{H}_{2} \mathrm{P}-\mathrm{DHPh}\right.$ COF]-[UiO-66] composite membrane to gas transport via straight COF channels, oriented perpendicularly to the membrane surface, which helps improve intracrystalline gas diffusion $^{37-39}$. The growth of a very compact $2 \mathrm{D}$ COF film helps to develop better grain structures, which productively cuts down non-selective intercrystalline gas diffusion ${ }^{37-39}$. Therefore by the rational selection of porous frameworks we obtained a specially designed membrane that demonstrates high gas flux combined with high selectivity.

To summarize, this study presents a general strategy for fabrication of oriented $2 \mathrm{D}$ COF membranes. The chemical synergy between the building components, their functionality, spatial arrangement and crystallographic orientation are the indispensable components that determine the exceptional performance of a membrane. The results of the present study illustrate that membranes with exceptional selectivity and ultrahigh permeability can be produced if the above issues are properly addressed. This research also provides a sustainable route for highly effective separation of $\mathrm{H}_{2}$ over $\mathrm{CO}_{2}$.

\section{ASSOCIATED CONTENT}

\section{Supporting Information}

Synthetic procedures, membrane fabrication, membrane illustration and characterization, FTIR, crystallographic preferred orientation (CPO), PXRD, TGA, BET plot, lowpressure gas sorption isotherms, gas permeation tests and results. This material is available free of charge via the internet at http://pubs.acs.org.

\section{AUTHOR INFORMATION}

\section{Corresponding Author}

*tben@jlu.edu.cn

\section{Notes}

The authors declare no competing financial interests.

\section{ACKNOWLEDGMENT}

This study was supported by the NSFC (21390394, 21471065, 21571078), Science and Technology Department of Jilin Province Foundation (20180414009GH). V.V. acknowledges the Thousand Talents program in China. T.B, S.Q. and V.V. acknowledge the support in the framework of China-French joint laboratory "Zeolites".

\section{REFERENCES}

(1) Fan, H.; Gu, J.; Meng, H.; Knebel, A.; Caro, J. Angew. Chem. Int. Ed. 2018, 57, 4083 .

(2) (a) Kandambeth, S.; Biswal, B. P.; Chaudhari, H. D.; Rout, K. C.; Kunjattu H., S.; Mitra, S.; Karak, S.; Das, A.; Mukherjee, R.; Kharul, U. K.; Banerjee, R. Adv. Mater. 2017, 29, 1603945. (b) Dey, K.; Pal, M.; Rout, K. C.; Kunjattu H., S.; Das, A.; Mukherjee, R.; Kharul, U. K.; Banerjee, R. J. Am. Chem. Soc. 2017, 139, 13083. (c) Biswal, B. P.; Chaudhari, H. D.; Banerjee, R.; Kharul, U. K. Chem. - Eur. J. 2016, 22, 4695 . 8433.

(3) Li, G.; Zhang, K.; Tsuru, T. ACS Appl. Mater. Interfaces 2017, 9,

(4) Zhang, W.; Zhang, L.; Zhao, H.; Li, B.; Ma, H. J. Mater. Chem. A 2018, DOI: 10.1039/C8TA04178D.

(5) Yang, H.; Wu, H.; Yao, Z.; Shi, B.; Xu, Z.; Cheng, X.; Pan, F.; Liu, G.; Jiang, Z.; Cao. X. J. Mater. Chem. A 2018, 6, 583.

(6) Lu, H.; Wang, C.; Chen, J.; Ge, R.; Leng, W.; Dong, B.; Huang, J.; Gao, Y. Chem. Commun. 2015, 51, 15562.

(7) Fu, J.; Das, S.; Xing, G.; Ben, T.; Valtchev, V.; Qiu, S. J. Am. Chem. Soc. 2016, 138, 7673 . 


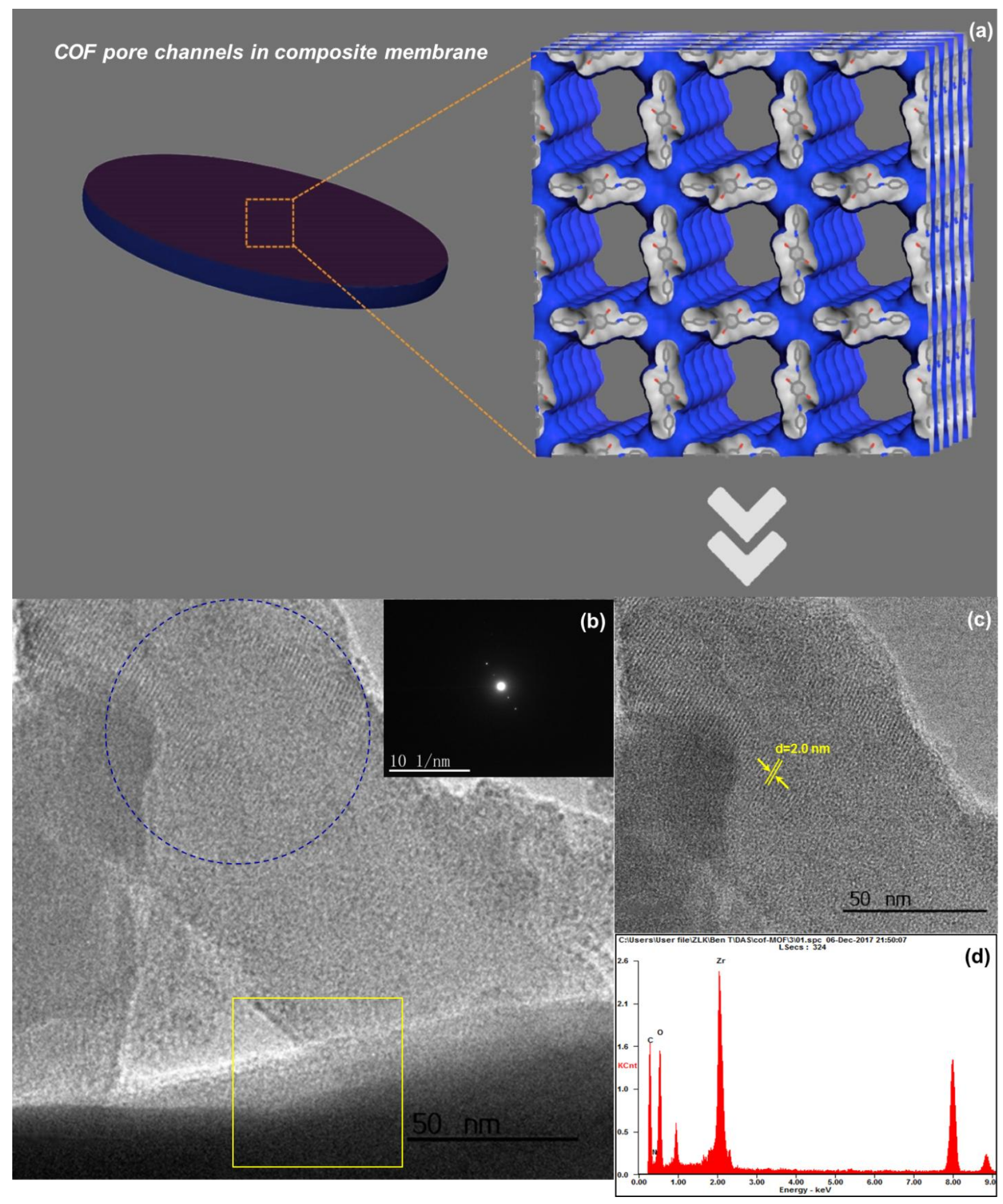

Figure 5. (a) COF pore channels in the composite membrane. (b) HRTEM image of the composite membrane. Inset: SAED pattern of the yellow marked area. (c) Magnified view (blue circle in b) of the COF channels with width of $2.0 \mathrm{~nm}$ in the composite membrane. (d) EDS spectrum of the composite membrane. 
(8) (a) Li, Y.; Yu, J. Chem. Rev. 2014, 114, 7268. (b) Weckhuysen, B. M.; Yu, J. Chem. Soc. Rev. 2015, 44, 7022.

(9) (a) Davis, M. E.; Lobo, R. F. Chem. Mater. 1992, 4, 756. (b) Davis, M. E. Chem. Mater. 2014, 26, 239.

(10) Li, J.; Corma, A.; Yu, J. Chem. Soc. Rev. 2015, 44, 7112.

(11) (a) O'Keeffe, M.; Yaghi, O. M. Chem. Rev. 2012, 112, 675. (b) Furukawa, H.; Cordova, K. E.; O’Keeffe, M.; Yaghi, O. M. Science 2o13, 341, 1230444. (c) Schoedel, A.; Li, M.; Li, D.; O’Keeffe, M.; Yaghi, O. M. Chem. Rev. 2016, 116, 12466.

(12) Furukawa, S.; Reboul, J.; Diring, S.; Sumida, K.; Kitagawa, S Chem. Soc. Rev. 2014, 43, 5700.

(13) Schneemann, A.; Bon, V.; Schwedler, I.; Senkovska, I.; Kaskel, S.; Fischer, R. A. Chem. Soc. Rev. 2014, 43, 6062.

(14) (a) Zhang, T.; Lin, W. Chem. Soc. Rev. 2014, 43, 5982. (b) Wang, C.; Liu, D.; Lin, W. J. Am. Chem. Soc. 2013, 135, 13222.

(15) Guillerm, V.; Kim, D.; Eubank, J. F.; Luebke, R.; Liu, X.; Adil, K.; Lah, M. S.; Eddaoudi, M. Chem. Soc. Rev. 2014, 43, 6141.

(16) Evans, J. D.; Sumby, C. J.; Doonan, C. J. Chem. Soc. Rev. 2014, 43, 5933 .

(17) Xomeritakis, G.; Lai, Z.; Tsapatsis, M. Ind. Eng. Chem. Res. 2001, 40,544

(18) Zhong, Z.; Yao, J.; Chen, R.; Low, Z.; He, M.; Liu, J. Z.; Wang, H. J. Mater. Chem. A 2015, 3, 15715.

(19) (a) Wang, Z.; Knebel, A.; Grosjean, S.; Wagner, D.; Bräse, S.; Wöll, C.; Caro, J.; Heinke, L. Nat. Commun. 2o16, 7 doi:10.1038/ncomms13872. (b) Ranjan, R.; Tsapatsis, M. Chem. Mater. 2009, 21, 4920. (c) Li, Y.; Liu, H.; Wang, H.; Qiu, J.; Zhang, X. Chem. Sci. 2018, 9, 4132

(20) Kim, H. W.; Yoon, H. W.; Yoon, S.-M.; Yoo, B. M.; Ahn, B. K.; Cho, Y. H.; Shin, H. J.; Yang, H.; Paik, U.; Kwon, S.; Choi, J.-Y.; Park, H. B. Science 2013, 342, 91.

(21) (a) Côté, A. P.; Benin, A. I.; Ockwig, N. W.; O'Keffe, M.; Matzger, A. J.; Yaghi, O. M. Science 2005, 310, 1166. (b) Côté, A. P.; ElKaderi, H. M.; Furukawa, H.; Hunt, J. R.; Yaghi, O. M. J. Am. Chem. Soc. 2007, 129, 12914. (c) Wan, S.; Gándara, F.; Asano, A.; Furukawa, H.; Saeki, A.; Dey, S. K.; Liao, L.; Ambrogio, M. W.; Botros, Y. Y.; Duan, X.; Seki, S.; Stoddart, J. F.; Yaghi, O. M. Chem. Mater. 2o11, 23, 4094 .

(22) (a) Feng, X.; Liu, L.; Honsho, Y.; Saeki, A.; Seki, S.; Irle, S.; Dong, Y.; Nagai, A.; Jiang, D. Angew. Chem. Int. Ed. 2012, 51, 2618. (b) Nagai, A.; Chen, X.; Feng, X.; Ding, X.; Guo, Z.; Jiang, D. Angew. Chem. Int. Ed. 2013, 52, 3770. (d) Jin, E.; Asada, M.; Xu, Q.; Dalapati,
S.; Addicoat, M. A.; Brady, M. A.; Xu, H.; Nakamura, T.; Heine, T.; Chen, Q.; Jiang, D. Science 2017, 357, 673.

(23) Evans, A. M.; Parent, L. R.; Flanders, N. C.; Bisbey, R. P.; Vitaku, E.; Kirschner, M. S.; Schaller, R. D.; Chen, L. X.; Gianneschi, N. C.; Dichtel, W. R. Science 2018, DOI: 10.1126/science.aar7883.

(24) Calik, M.; Auras, F.; Salonen, L. M.; Bader, K.; Grill, I.; Handloser, M.; Medina, D. D.; Dogru, M.; Löbermann, F.; Trauner, D.; Hartschuh, A.; Bein, T. J. Am. Chem. Soc. 2014, 136, 17802.

(25) Liao, H.; Wang, H.; Ding, H.; Meng, X.; Xu, H.; Wang, B.; Ai, X.; Wang, C. J. Mater. Chem. A 2016, 4, 7416.

(26) Mandal, A. K.; Mahmood, J.; Baek, J.-B. ChemNanoMat 2o17, 3, 373 .

(27) Robeson, L. M. J. Membr. Sci. 20o8, 320, 390.

(28) Cavka, J. H.; S. Jakobsen, U. Olsbye, N. Guillou, C. Lamberti, S. Bordiga, K. P. Lillerud, J. Am. Chem. Soc. 2oo8, 130, 13850-13851.

(29) Jeong, H.-K.; Krohn, J.; Sujaoti, K.; Tsapatsis, M. J. Am. Chem. Soc. 2002, 124, 12966.

(30) Verduijn, J. P.; Bons, A.-J.; Anthonis, M. H. C.; Czarnetzki, L. R. Int. Pat. Appl. PCT WO 96/o1683 (1996).

(31) Friebe, S.; Geppert, B.; Steinbach, F.; Caro, J. ACS Appl. Mater. Interfaces 2017, 9, 12878 .

(32) Das, S.; Ben, T. Dalton Trans. 2018, 47, 7206.

(33) Du, N.; Robertson, G. P.; Song, J.; Pinnau, I.; Guiver, M. D. Macromolecules 2009, 42, 6038.

(34) Shekhah, O.; Swaidan, R.; Belmabkhout, Y.; du Plessis, M.; Jacobs, T.; Barbour, L. J.; Pinnau, I.; Eddaoudi, M. Chem. Commun. 2014, 50, 2089.

(35) Huang, A.; Bux, H.; Steinbach, F.; Caro, J. Angew. Chem. Int. Ed. 2010, 49, 4958 .

(36) Zhou, S.; Zou, X.; Sun, F.; Ren, H.; Liu, J.; Zhang, F.; Zhao, N.; Zhu, G. Int. J. Hydrogen Energy 2013, 38, 5338.

(37) Yoo, Y.; Lai, Z.; Jeong, H.-K. Micro. Meso. Mater. 20o9, 123, 100.

(38) Lai, Z.; Bonilla, G.; Diaz, I.; Nery, J. G.; Sujaoti, K.; Amat, M. A.; Kokkoli, E.; Terasaki, O.; Thompson, R. W.; Tsapatsis, M.; Vlachos, D. G. Science 2003, 300, 456.

(39) Lai, Z.; Tsapatsis, M.; Nicolich, J. P. Adv. Funct. Mater. 2oo4, $14,716$.

\section{TOC Graphic:}

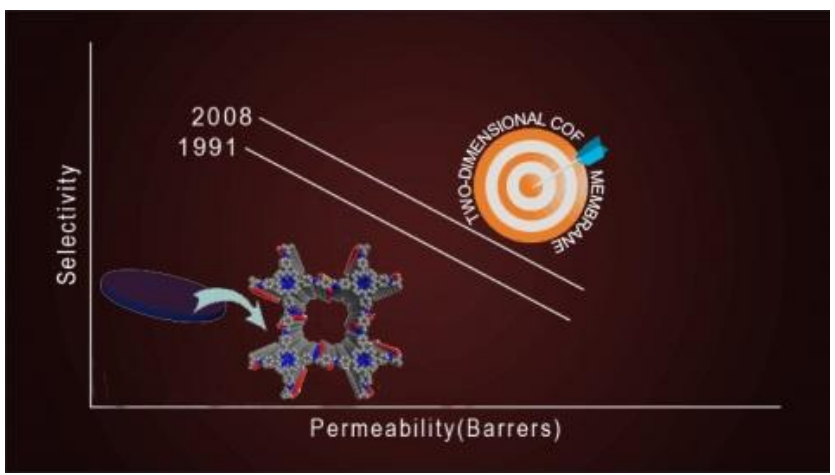

